\title{
ESG 2015
}

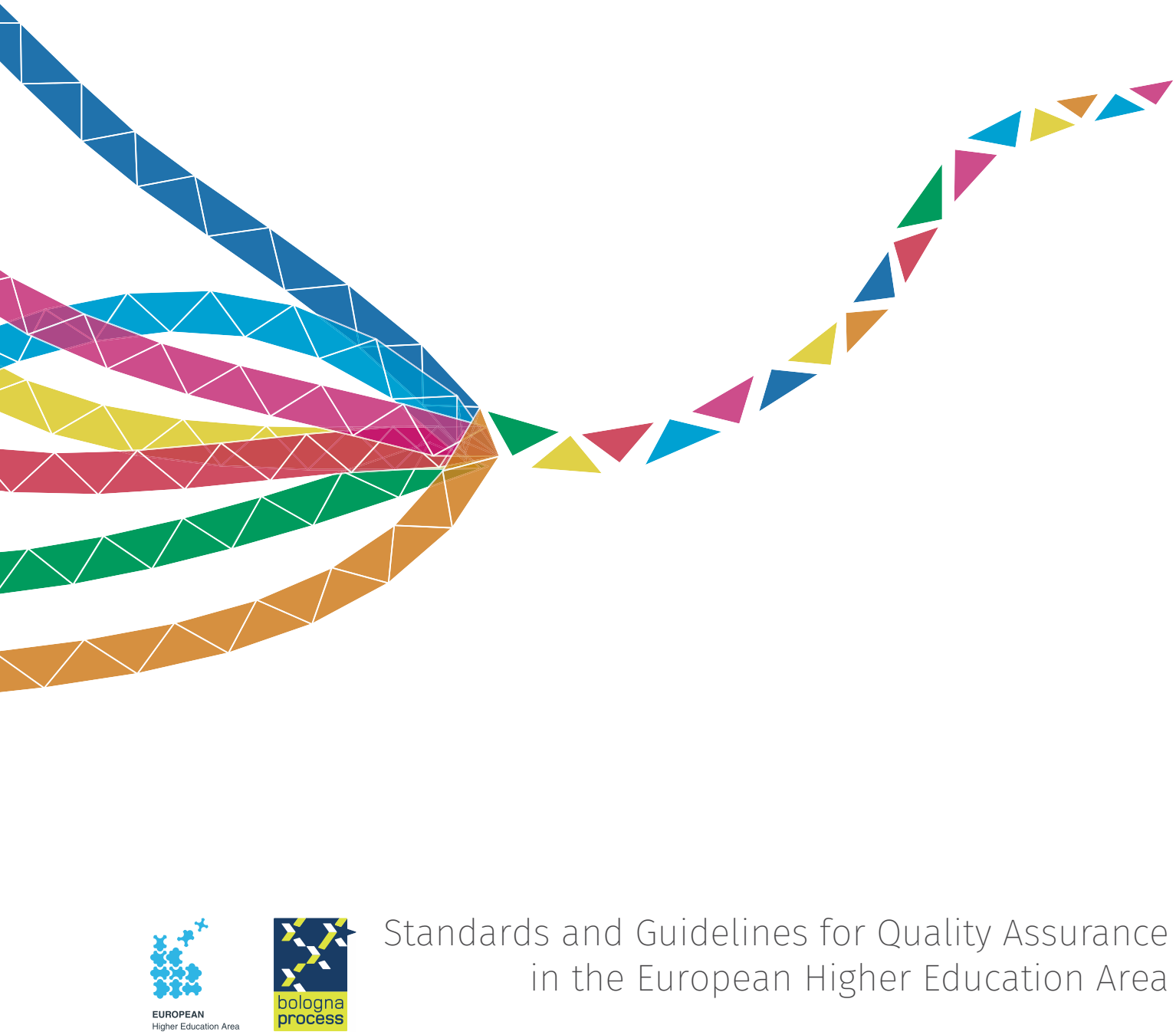



Standards and Guidelines for Quality Assurance in the

European Higher Education Area (ESG) 


\section{Please cite this publication as:}

Standards and Guidelines for Quality Assurance in the European Higher Education Area (ESG). (2015). Brussels, Belgium.

ISBN: 978-9-08-168672-3

Legal deposit: D/2015/13.742/1

\section{Authors:}

European Association for Quality Assurance in Higher Education (ENQA)

European Students' Union (ESU)

European University Association (EUA)

European Association of Institutions in Higher Education (EURASHE)

In cooperation with:

Education International (EI)

BUSINESSEUROPE

European Quality Assurance Register for Higher Education (EQAR)

Design \& Publication:

by EURASHE, on behalf of the authors. Brussels, Belgium. 2015

cc)()(2) This work is licensed under the Creative Commons Attribution-NonCommercial-ShareAlike 4.0 International License. To view a copy of this license, visit http://creativecommons.org/ licenses/by-nc-sa/4.0/.

Printed with the support of the EU-funded EQUIP project.

The EQUIP project, is an EU-funded project, that aims at Enhancing Quality through Innovative Policy \& Practice in European higher education by promoting the consistent, efficient and innovative embedding of the ESG at grass-root level. The EQUIP partners are EURASHE, ENQA, EUA, ESU, El Research Institute, EQAR, UiO IPED and CCISP.

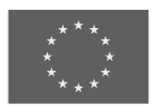

Co-funded by the

Erasmus+ Programme of the European Union
The European Commission support for the production of this publication does not constitute an endorsement of the contents which reflects the views only of the authors, and the Commission cannot be held responsible for any use which may be made of the information contained therein. 


\section{Table of Contents}

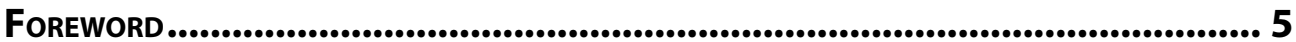

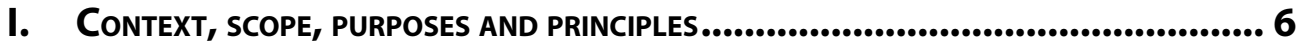

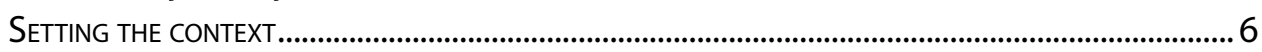

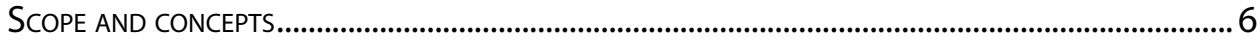

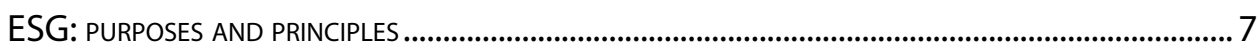

II. EUROPEAN STANDARDS AND GUIDELINES FOR QUALITY ASSURANCE IN HIGHER

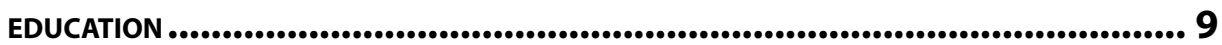

PART 1: STANDARDS AND GUIDELINES FoR INTERNAL QUALITY ASSURANCE ..........................................10

PART 2: StANDARDS AND GUIDELINES FoR EXTERNAL QUALITY ASSURANCE...........................................17

Part 3: StANDARDS AND GUIDELINES For QUality ASSURANCE AGENCIES ............................................21

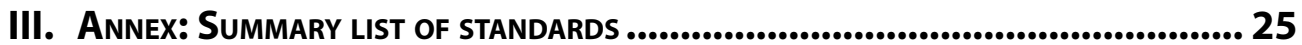





\title{
FOREWORD
}

The Standards and Guidelines for Quality Assurance in the European Higher Education Area (ESG) were adopted by the Ministers responsible for higher education in 2005 following a proposal prepared by the European Association for Quality Assurance in Higher Education (ENQA) in cooperation with the European Students' Union (ESU), ${ }^{1}$ the European Association of Institutions in Higher Education (EURASHE) and the European University Association (EUA).

Since 2005 , considerable progress has been made in quality assurance as well as in other Bologna action lines such as qualifications frameworks, recognition and the promotion of the use of learning outcomes, all these contributing to a paradigm shift towards student-centred learning and teaching.

Given this changing context, in 2012 the Ministerial Communiqué invited the E4 Group (ENQA, ESU, EUA, EURASHE) in cooperation with Education International (EI), BUSINESSEUROPE and the European Quality Assurance Register for Higher Education (EQAR) to prepare an initial proposal for a revised ESG "to improve their clarity, applicability and usefulness, including their scope".

The revision included several consultation rounds involving both the key stakeholder organisations and ministries. The many comments, proposals and recommendations received were carefully analysed and taken very seriously by the Steering Group (SG). They are reflected in this 2015 version of the ESG.

The ESG 2015 were adopted by the Ministers responsible for higher education in the European Higher Education Area in May 2015. As a result of the participative revision we are confident that they reflect a consensus among all the organisations and ministries involved on how to take forward quality assurance in the European Higher Education Area and, as such, provide a firm basis for successful implementation.

\author{
European Association for Quality Assurance in Higher Education (ENQA) \\ European Students' Union (ESU) \\ European University Association (EUA) \\ European Association of Institutions in Higher Education (EURASHE) \\ In cooperation with: \\ Education International (El) \\ BUSINESSEUROPE \\ European Quality Assurance Register for Higher Education (EQAR)
}

1 ESU was formerly known as ESIB - The National Unions of Students in Europe. 


\section{ConteXt, SCOPE, PURPOSES AND PRINCIPLES}

\section{Setting THE CONTEXT}

Higher education, research and innovation play a crucial role in supporting social cohesion, economic growth and global competitiveness. Given the desire for European societies to become increasingly knowledge-based, higher education is an essential component of socio-economic and cultural development. At the same time, an increasing demand for skills and competences requires higher education to respond in new ways.

Broader access to higher education is an opportunity for higher education institutions to make use of increasingly diverse individual experiences. Responding to diversity and growing expectations for higher education requires a fundamental shift in its provision; it requires a more student-centred approach to learning and teaching, embracing flexible learning paths and recognising competences gained outside formal curricula. Higher education institutions themselves also become more diverse in their missions, mode of educational provision and cooperation, including growth of internationalisation, digital learning and new forms of delivery. ${ }^{2}$ The role of quality assurance is crucial in supporting higher education systems and institutions in responding to these changes while ensuring the qualifications achieved by students and their experience of higher education remain at the forefront of institutional missions.

A key goal of the Standards and Guidelines for Quality Assurance in the European Higher Education Area (ESG) is to contribute to the common understanding of quality assurance for learning and teaching across borders and among all stakeholders. ${ }^{3}$ They have played and will continue to play an important role in the development of national and institutional quality assurance systems across the European Higher Education Area (EHEA) and cross-border cooperation. Engagement with quality assurance processes, particularly the external ones, allows European higher education systems to demonstrate quality and increase transparency, thus helping to build mutual trust and better recognition of their qualifications, programmes ${ }^{4}$ and other provision.

The ESG are used by institutions and quality assurance agencies as a reference document for internal and external quality assurance systems in higher education. Moreover, they are used by the European Quality Assurance Register (EQAR), which is responsible for the register of quality assurance agencies that comply with the ESG.

\section{SCOPE AND CONCEPTS}

The ESG are a set of standards and guidelines for internal and external quality assurance in higher education. The ESG are not standards for quality, nor do they prescribe how the quality assurance processes are implemented, but they provide guidance, covering the areas which are vital for successful quality provision and learning environments in higher education. The ESG should be considered in a broader context that also includes qualifications frameworks, ECTS and diploma supplement that also contribute to promoting the transparency and mutual trust in higher education in the EHEA.

2 Communication from the European Commission: Opening up Education: Innovative teaching and learning for all through new Technologies and Open Educational Resources, $\operatorname{COM(2013)~} 654$ final, http://ec.europa. eu/education/news/doc/openingcom_en.pdf

3 Unless otherwise specified, in the document stakeholders are understood to cover all actors within an institution, including students and staff, as well as external stakeholders such as employers and external partners of an institution.

4 The term "programme" in these standards refers to higher education provision in its broadest sense, including provision that is not part of a programme leading to a formal degree. 
The focus of the ESG is on quality assurance related to learning and teaching in higher education, including the learning environment and relevant links to research and innovation. In addition institutions have policies and processes to ensure and improve the quality of their other activities, such as research and governance.

The ESG apply to all higher education offered in the EHEA regardless of the mode of study or place of delivery. Thus, the ESG are also applicable to all higher education including transnational and cross-border provision. In this document the term "programme" refers to higher education in its broadest sense, including that which is not part of a programme leading to a formal degree.

Higher education aims to fulfil multiple purposes; including preparing students for active citizenship, for their future careers (e.g. contributing to their employability), supporting their personal development, creating a broad advanced knowledge base and stimulating research and innovation. ${ }^{5}$ Therefore, stakeholders, who may prioritise different purposes, can view quality in higher education differently and quality assurance needs to take into account these different perspectives. Quality, whilst not easy to define, is mainly a result of the interaction between teachers, students and the institutional learning environment. Quality assurance should ensure a learning environment in which the content of programmes, learning opportunities and facilities are fit for purpose.

At the heart of all quality assurance activities are the twin purposes of accountability and enhancement. Taken together, these create trust in the higher education institution's performance. A successfully implemented quality assurance system will provide information to assure the higher education institution and the public of the quality of the higher education institution's activities (accountability) as well as provide advice and recommendations on how it might improve what it is doing (enhancement). Quality assurance and quality enhancement are thus inter-related. They can support the development of a quality culture that is embraced by all: from the students and academic staff to the institutional leadership and management.

The term 'quality assurance' is used in this document to describe all activities within the continuous improvement cycle (i.e. assurance and enhancement activities).

Unless otherwise specified, in the document stakeholders are understood to cover all actors within an institution, including students and staff, as well as external stakeholders such as employers and external partners of an institution.

The word institution is used in the standards and guidelines to refer to higher education institutions. Depending on the institution's approach to quality assurance it can, however, refer to the institution as whole or to any actors within the institution.

\section{ESG: PURPOSES AND PRINCIPLES}

The ESG have the following purposes:

- They set a common framework for quality assurance systems for learning and teaching at European, national and institutional level;

- They enable the assurance and improvement of quality of higher education in the European higher education area;

- They support mutual trust, thus facilitating recognition and mobility within and across national borders;

- They provide information on quality assurance in the EHEA.

5 Recommendation $\operatorname{Rec}$ (2007)6 by the Council of Europe's Committee of Ministers on the public responsibility for higher education and research, http://www.coe.int/t/dg4/highereducation/News/pub_res_EN.pdf 
These purposes provide a framework within which the ESG may be used and implemented in different ways by different institutions, agencies and countries. The EHEA is characterised by its diversity of political systems, higher education systems, socio-cultural and educational traditions, languages, aspirations and expectations. This makes a single monolithic approach to quality and quality assurance in higher education inappropriate. Broad acceptance of all standards is a precondition for creating common understanding of quality assurance in Europe. For these reasons, the ESG need to be at a reasonably generic level in order to ensure that they are applicable to all forms of provision.

The ESG provide the criteria at European level against which quality assurance agencies and their activities are assessed. ${ }^{6}$ This ensures that the quality assurance agencies in the EHEA adhere to the same set of principles and the processes and procedures are modelled to fit the purposes and requirements of their contexts.

The ESG are based on the following four principles for quality assurance in the EHEA:

- Higher education institutions have primary responsibility for the quality of their provision and its assurance;

- Quality assurance responds to the diversity of higher education systems, institutions, programmes and students;

- Quality assurance supports the development of a quality culture;

- Quality assurance takes into account the needs and expectations of students, all other stakeholders and society.

6 Agencies that apply for inclusion in the European Quality Assurance Register (EQAR) undergo an external review for which the ESG provide the criteria. Also the European Association for Quality Assurance in Higher Education (ENQA) relies on compliance with the ESG when it comes to granting quality assurance agencies full membership status in the organisation. 


\section{EUROPEAN STANDARDS AND GUIDELINES FOR QUALITY ASSURANCE IN HIGHER EDUCATION}

The standards for quality assurance have been divided into three parts:

- Internal quality assurance

- External quality assurance

- Quality assurance agencies

It should be kept in mind, however, that the three parts are intrinsically interlinked and together form the basis for a European quality assurance framework. External quality assurance in Part 2 recognises the standards for internal quality assurance in Part 1 thus ensuring that the internal work undertaken by institutions is directly relevant to any external quality assurance that they undergo. In the same way Part 3 refers to Part 2. Thus, these three parts work on a complementary basis in higher education institutions as well as in agencies and also work on the understanding that other stakeholders contribute to the framework. As a consequence, the three parts should be read as a whole.

The standards set out agreed and accepted practice for quality assurance in higher education in the EHEA and should, therefore, be taken account of and adhered to by those concerned, in all types of higher education provision. ${ }^{7}$ The summary list of standards for quality assurance is placed in the annex for easy reference.

The guidelines explain why the standard is important and describe how standards might be implemented. They set out good practice in the relevant area for consideration by the actors involved in quality assurance. Implementation will vary depending on different contexts.

7 The standards make use of the common English usage of "should" which has the connotation of prescription and compliance. 
Part 1: Standards and guidelines for internal quality assurance 


\subsection{Policy for Quality assurance}

STANDARD:

Institutions should have a policy for quality assurance that is made public and forms part of their strategic management. Internal stakeholders should develop and implement this policy through appropriate structures and processes, while involving external stakeholders.

\section{GUIDELINES:}

Policies and processes are the main pillars of a coherent institutional quality assurance system that forms a cycle for continuous improvement and contributes to the accountability of the institution. It supports the development of quality culture in which all internal stakeholders assume responsibility for quality and engage in quality assurance at all levels of the institution. In order to facilitate this, the policy has a formal status and is publicly available.

Quality assurance policies are most effective when they reflect the relationship between research and learning \& teaching and take account of both the national context in which the institution operates, the institutional context and its strategic approach. Such a policy supports

- the organisation of the quality assurance system;

- departments, schools, faculties and other organisational units as well as those of institutional leadership, individual staff members and students to take on their responsibilities in quality assurance;

- academic integrity and freedom and is vigilant against academic fraud;

- guarding against intolerance of any kind or discrimination against the students or staff;

- the involvement of external stakeholders in quality assurance.

The policy translates into practice through a variety of internal quality assurance processes that allow participation across the institution. How the policy is implemented, monitored and revised is the institution's decision.

The quality assurance policy also covers any elements of an institution's activities that are subcontracted to or carried out by other parties.

\subsection{Design AND approval of PROgrammes}

\section{STANDARD:}

Institutions should have processes for the design and approval of their programmes. The programmes should be designed so that they meet the objectives set for them, including the intended learning outcomes. The qualification resulting from a programme should be clearly specified and communicated, and refer to the correct level of the national qualifications framework for higher education and, consequently, to the Framework for Qualifications of the European Higher Education Area.

\section{GUIDELINES:}

Study programmes are at the core of the higher education institutions' teaching mission. They provide students with both academic knowledge and skills including those that are transferable, which may influence their personal development and may be applied in their future careers.

\section{Programmes}

- are designed with overall programme objectives that are in line with the institutional strategy and have explicit intended learning outcomes;

- are designed by involving students and other stakeholders in the work; 
- benefit from external expertise and reference points;

reflect the four purposes of higher education of the Council of Europe (cf. Scope and Concepts);

are designed so that they enable smooth student progression;

define the expected student workload, e.g. in ECTS;

include well-structured placement opportunities where appropriate; ${ }^{8}$

are subject to a formal institutional approval process.

\subsection{Student-Centred LEARNING, TEACHING AND ASSESSMENT}

\section{STANDARD:}

Institutions should ensure that the programmes are delivered in a way that encourages students to take an active role in creating the learning process, and that the assessment of students reflects this approach.

\section{GUIDELINES:}

Student-centred learning and teaching plays an important role in stimulating students' motivation, self-reflection and engagement in the learning process. This means careful consideration of the design and delivery of study programmes and the assessment of outcomes.

The implementation of student-centred learning and teaching

- respects and attends to the diversity of students and their needs, enabling flexible learning paths;

- considers and uses different modes of delivery, where appropriate;

- flexibly uses a variety of pedagogical methods;

- regularly evaluates and adjusts the modes of delivery and pedagogical methods;

- encourages a sense of autonomy in the learner, while ensuring adequate guidance and support from the teacher;

- promotes mutual respect within the learner-teacher relationship;

- has appropriate procedures for dealing with students' complaints.

Considering the importance of assessment for the students' progression and their future careers, quality assurance processes for assessment take into account the following:

- Assessors are familiar with existing testing and examination methods and receive support in developing their own skills in this field;

- The criteria for and method of assessment as well as criteria for marking are published in advance;

- The assessment allows students to demonstrate the extent to which the intended learning outcomes have been achieved. Students are given feedback, which, if necessary, is linked to advice on the learning process;

- Where possible, assessment is carried out by more than one examiner;

- The regulations for assessment take into account mitigating circumstances;

- Assessment is consistent, fairly applied to all students and carried out in accordance with the stated procedures;

- A formal procedure for student appeals is in place.

8 Placements include traineeships, internships and other periods of the programme that are not spent in the institution but that allow the student to gain experience in an area related to their studies. 


\subsection{StUdent ADMISSION, PROGRESSION, RECOGNITION AND CERTIFICATION}

\section{STANDARD:}

Institutions should consistently apply pre-defined and published regulations covering all phases of the student "life cycle", e.g. student admission, progression, recognition and certification.

\section{GUIDELINES:}

Providing conditions and support that are necessary for students to make progress in their academic career is in the best interest of the individual students, programmes, institutions and systems. It is vital to have fit-for-purpose admission, recognition and completion procedures, particularly when students are mobile within and across higher education systems.

It is important that access policies, admission processes and criteria are implemented consistently and in a transparent manner. Induction to the institution and the programme is provided.

Institutions need to put in place both processes and tools to collect, monitor and act on information on student progression.

Fair recognition of higher education qualifications, periods of study and prior learning, including the recognition of non-formal and informal learning, are essential components for ensuring the students' progress in their studies, while promoting mobility. Appropriate recognition procedures rely on

- institutional practice for recognition being in line with the principles of the Lisbon Recognition Convention;

- cooperation with other institutions, quality assurance agencies and the national ENIC/NARIC centre with a view to ensuring coherent recognition across the country.

Graduation represents the culmination of the students' period of study. Students need to receive documentation explaining the qualification gained, including achieved learning outcomes and the context, level, content and status of the studies that were pursued and successfully completed.

\subsection{Teaching stafF}

\section{STANDARD:}

Institutions should assure themselves of the competence of their teachers. They should apply fair and transparent processes for the recruitment and development of the staff.

\section{GUIDELINES:}

The teacher's role is essential in creating a high quality student experience and enabling the acquisition of knowledge, competences and skills. The diversifying student population and stronger focus on learning outcomes require student-centred learning and teaching and the role of the teacher is, therefore, also changing (cf. Standard 1.3).

Higher education institutions have primary responsibility for the quality of their staff and for providing them with a supportive environment that allows them to carry out their work effectively. Such an environment

- sets up and follows clear, transparent and fair processes for staff recruitment and conditions of employment that recognise the importance of teaching;

- offers opportunities for and promotes the professional development of teaching staff;

- encourages scholarly activity to strengthen the link between education and research;

- encourages innovation in teaching methods and the use of new technologies. 


\subsection{LEARNING RESOURCES AND STUDENT SUPPORT}

\section{STANDARD:}

Institutions should have appropriate funding for learning and teaching activities and ensure that adequate and readily accessible learning resources and student support are provided.

\section{GUIDELINES:}

For a good higher education experience, institutions provide a range of resources to assist student learning. These vary from physical resources such as libraries, study facilities and IT infrastructure to human support in the form of tutors, counsellors and other advisers. The role of support services is of particular importance in facilitating the mobility of students within and across higher education systems.

The needs of a diverse student population (such as mature, part-time, employed and international students as well as students with disabilities), and the shift towards student-centred learning and flexible modes of learning and teaching, are taken into account when allocating, planning and providing the learning resources and student support.

Support activities and facilities may be organised in a variety of ways depending on the institutional context. However, the internal quality assurance ensures that all resources are fit for purpose, accessible, and that students are informed about the services available to them.

In delivering support services the role of support and administrative staff is crucial and therefore they need to be qualified and have opportunities to develop their competences.

\subsection{INFORMATION MANAGEMENT}

\section{STANDARD:}

Institutions should ensure that they collect, analyse and use relevant information for the effective management of their programmes and other activities.

\section{GUIDELINES:}

Reliable data is crucial for informed decision-making and for knowing what is working well and what needs attention. Effective processes to collect and analyse information about study programmes and other activities feed into the internal quality assurance system.

The information gathered depends, to some extent, on the type and mission of the institution. The following are of interest:

- Key performance indicators;

- Profile of the student population;

- Student progression, success and drop-out rates;

- Students' satisfaction with their programmes;

- Learning resources and student support available;

- Career paths of graduates.

Various methods of collecting information may be used. It is important that students and staff are involved in providing and analysing information and planning follow-up activities. 


\subsection{Public information}

STANDARD:

Institutions should publish information about their activities, including programmes, which is clear, accurate, objective, up-to date and readily accessible.

\section{GUIDELINES:}

Information on institutions' activities is useful for prospective and current students as well as for graduates, other stakeholders and the public.

Therefore, institutions provide information about their activities, including the programmes they offer and the selection criteria for them, the intended learning outcomes of these programmes, the qualifications they award, the teaching, learning and assessment procedures used, the pass rates and the learning opportunities available to their students as well as graduate employment information.

\subsection{ON-GOING MONITORING AND PERIODIC REVIEW OF PROGRAMMES}

\section{STANDARD:}

Institutions should monitor and periodically review their programmes to ensure that they achieve the objectives set for them and respond to the needs of students and society. These reviews should lead to continuous improvement of the programme. Any action planned or taken as a result should be communicated to all those concerned.

\section{GUIDELINES:}

Regular monitoring, review and revision of study programmes aim to ensure that the provision remains appropriate and to create a supportive and effective learning environment for students.

They include the evaluation of:

- The content of the programme in the light of the latest research in the given discipline thus ensuring that the programme is up to date;

- The changing needs of society;

- The students' workload, progression and completion;

- The effectiveness of procedures for assessment of students;

- The student expectations, needs and satisfaction in relation to the programme;

- The learning environment and support services and their fitness for purpose for the programme.

Programmes are reviewed and revised regularly involving students and other stakeholders. The information collected is analysed and the programme is adapted to ensure that it is up-to-date. Revised programme specifications are published.

\subsection{CyCLICAL EXTERNAL QUALITY ASSURANCE}

\section{STANDARD:}

Institutions should undergo external quality assurance in line with the ESG on a cyclical basis.

\section{GUIDELINES:}

External quality assurance in its various forms can verify the effectiveness of institutions' internal quality assurance, act as a catalyst for improvement and offer the institution new perspectives. It will also provide information to assure the institution and the public of the quality of the institution's activities. 
Institutions participate in cyclical external quality assurance that takes account, where relevant, of the requirements of the legislative framework in which they operate. Therefore, depending on the framework, this external quality assurance may take different forms and focus at different organisational levels (such as programme, faculty or institution).

Quality assurance is a continuous process that does not end with the external feedback or report or its follow-up process within the institution. Therefore, institutions ensure that the progress made since the last external quality assurance activity is taken into consideration when preparing for the next one. 


\section{Part 2: Standards and guidelines for external quality assurance}




\subsection{Consideration of Internal Quality assurance}

\section{StANDARD:}

External quality assurance should address the effectiveness of the internal quality assurance processes described in Part 1 of the ESG.

\section{GUIDELINES:}

Quality assurance in higher education is based on the institutions' responsibility for the quality of their programmes and other provision; therefore it is important that external quality assurance recognises and supports institutional responsibility for quality assurance. To ensure the link between internal and external quality assurance, external quality assurance includes consideration of the standards of Part 1. These may be addressed differently, depending on the type of external quality assurance.

\subsection{Designing MEthodologies fit FOR PURPOSE}

\section{STANDARD:}

External quality assurance should be defined and designed specifically to ensure its fitness to achieve the aims and objectives set for it, while taking into account relevant regulations. Stakeholders should be involved in its design and continuous improvement.

\section{GUIDELINES:}

In order to ensure effectiveness and objectivity it is vital for external quality assurance to have clear aims agreed by stakeholders.

The aims, objectives and implementation of the processes will

- bear in mind the level of workload and cost that they will place on institutions;

- take into account the need to support institutions to improve quality;

- allow institutions to demonstrate this improvement;

- result in clear information on the outcomes and the follow-up.

The system for external quality assurance might operate in a more flexible way if institutions are able to demonstrate the effectiveness of their own internal quality assurance.

\subsection{IMPLEMENTING PROCESSES}

\section{STANDARD:}

External quality assurance processes should be reliable, useful, pre-defined, implemented consistently and published. They include

- a self-assessment or equivalent;

- an external assessment normally including a site visit;

- a report resulting from the external assessment;

- a consistent follow-up.

\section{GuideLINEs:}

External quality assurance carried out professionally, consistently and transparently ensures its acceptance and impact.

Depending on the design of the external quality assurance system, the institution provides the basis 
for the external quality assurance through a self-assessment or by collecting other material including supporting evidence. The written documentation is normally complemented by interviews with stakeholders during a site visit. The findings of the assessment are summarised in a report (cf. Standard 2.5) written by a group of external experts (cf. Standard 2.4).

External quality assurance does not end with the report by the experts. The report provides clear guidance for institutional action. Agencies have a consistent follow-up process for considering the action taken by the institution. The nature of the follow-up will depend on the design of the external quality assurance.

\subsection{Peer-Review experts}

\section{STANDARD:}

External quality assurance should be carried out by groups of external experts that include (a) student member(s).

\section{GUIDELINES:}

At the core of external quality assurance is the wide range of expertise provided by peer experts, who contribute to the work of the agency through input from various perspectives, including those of institutions, academics, students and employers/professional practitioners.

In order to ensure the value and consistency of the work of the experts, they

- are carefully selected;

- have appropriate skills and are competent to perform their task;

- are supported by appropriate training and/or briefing.

The agency ensures the independence of the experts by implementing a mechanism of no-conflictof-interest.

The involvement of international experts in external quality assurance, for example as members of peer panels, is desirable as it adds a further dimension to the development and implementation of processes.

\subsection{Criteria for OUtComes}

\section{STANDARD:}

Any outcomes or judgements made as the result of external quality assurance should be based on explicit and published criteria that are applied consistently, irrespective of whether the process leads to a formal decision.

\section{GUIDELINES:}

External quality assurance and in particular its outcomes have a significant impact on institutions and programmes that are evaluated and judged.

In the interests of equity and reliability, outcomes of external quality assurance are based on pre-defined and published criteria, which are interpreted consistently and are evidence-based. Depending on the external quality assurance system, outcomes may take different forms, for example, recommendations, judgements or formal decisions. 


\subsection{Reporting}

\section{StANDARD:}

Full reports by the experts should be published, clear and accessible to the academic community, external partners and other interested individuals. If the agency takes any formal decision based on the reports, the decision should be published together with the report.

\section{GUIDELINES:}

The report by the experts is the basis for the institution's follow-up action of the external evaluation and it provides information to society regarding the activities of an institution. In order for the report to be used as the basis for action to be taken, it needs to be clear and concise in its structure and language and to cover

- context description (to help locate the higher education institution in its specific context);

- description of the individual procedure, including experts involved;

- evidence, analysis and findings;

- conclusions;

- features of good practice, demonstrated by the institution;

- recommendations for follow-up action.

The preparation of a summary report may be useful.

The factual accuracy of a report is improved if the institution is given the opportunity to point out errors of fact before the report is finalised.

\subsection{Complaints AND APPeals}

\section{STANDARD:}

Complaints and appeals processes should be clearly defined as part of the design of external quality assurance processes and communicated to the institutions.

\section{GUIDELINES:}

In order to safeguard the rights of the institutions and ensure fair decision-making, external quality assurance is operated in an open and accountable way. Nevertheless, there may be misapprehensions or instances of dissatisfaction about the process or formal outcomes.

Institutions need to have access to processes that allow them to raise issues of concern with the agency; the agencies, need to handle such issues in a professional way by means of a clearly defined process that is consistently applied.

A complaints procedure allows an institution to state its dissatisfaction about the conduct of the process or those carrying it out.

In an appeals procedure, the institution questions the formal outcomes of the process, where it can demonstrate that the outcome is not based on sound evidence, that criteria have not been correctly applied or that the processes have not been consistently implemented. 


\section{Part 3: Standards and guidelines for quality assurance agencies}




\subsection{ACtivities, POLICY AND PROCESSES For QUALITY ASSURANCE}

\section{StANDARD:}

Agencies should undertake external quality assurance activities as defined in Part 2 of the ESG on a regular basis. They should have clear and explicit goals and objectives that are part of their publicly available mission statement. These should translate into the daily work of the agency. Agencies should ensure the involvement of stakeholders in their governance and work.

\section{GUIDELINES:}

To ensure the meaningfulness of external quality assurance, it is important that institutions and the public trust agencies.

Therefore, the goals and objectives of the quality assurance activities are described and published along with the nature of interaction between the agencies and relevant stakeholders in higher education, especially the higher education institutions, and the scope of the agencies' work. The expertise in the agency may be increased by including international members in agency committees.

A variety of external quality assurance activities are carried out by agencies to achieve different objectives. Among them are evaluation, review, audit, assessment, accreditation or other similar activities at programme or institutional level that may be carried out differently. When the agencies also carry out other activities, a clear distinction between external quality assurance and their other fields of work is needed.

\subsection{Official status}

\section{STANDARD:}

Agencies should have an established legal basis and should be formally recognised as quality assurance agencies by competent public authorities.

\section{Guidelines:}

In particular when external quality assurance is carried out for regulatory purposes, institutions need to have the security that the outcomes of this process are accepted within their higher education system, by the state, the stakeholders and the public.

\subsection{INDEPENDENCE}

\section{STANDARD:}

Agencies should be independent and act autonomously. They should have full responsibility for their operations and the outcomes of those operations without third party influence.

\section{GUIDELINES:}

Autonomous institutions need independent agencies as counterparts.

In considering the independence of an agency the following are important:

- Organisational independence, demonstrated by official documentation (e.g. instruments of government, legislative acts or statutes of the organisation) that stipulates the independence of the agency's work from third parties, such as higher education institutions, governments and other stakeholder organisations;

- Operational independence: the definition and operation of the agency's procedures and 
methods as well as the nomination and appointment of external experts are undertaken independently from third parties such as higher education institutions, governments and other stakeholders;

- Independence of formal outcomes: while experts from relevant stakeholder backgrounds, particularly students, take part in quality assurance processes, the final outcomes of the quality assurance processes remain the responsibility of the agency.

Anyone contributing to external quality assurance activities of an agency (e.g. as expert) is informed that while they may be nominated by a third party, they are acting in a personal capacity and not representing their constituent organisations when working for the agency. Independence is important to ensure that any procedures and decisions are solely based on expertise.

\subsection{Thematic ANALysis}

\section{StANDARD:}

Agencies should regularly publish reports that describe and analyse the general findings of their external quality assurance activities.

\section{Guidelines:}

In the course of their work, agencies gain information on programmes and institutions that can be useful beyond the scope of a single process, providing material for structured analyses across the higher education system. These findings can contribute to the reflection on and the improvement of quality assurance policies and processes in institutional, national and international contexts.

A thorough and careful analysis of this information will show developments, trends and areas of good practice or persistent difficulty.

\subsection{Resources}

\section{StANDARD:}

Agencies should have adequate and appropriate resources, both human and financial, to carry out their work.

\section{GuideLines:}

It is in the public interest that agencies are adequately and appropriately funded, given higher education's important impact on the development of societies and individuals. The resources of the agencies enable them to organise and run their external quality assurance activities in an effective and efficient manner. Furthermore, the resources enable the agencies to improve, to reflect on their practice and to inform the public about their activities.

\subsection{INTERNAL QUALITY ASSURANCE AND PROFESSIONAL CONDUCT}

\section{StANDARD:}

Agencies should have in place processes for internal quality assurance related to defining, assuring and enhancing the quality and integrity of their activities.

\section{Guidelines:}

Agencies need to be accountable to their stakeholders. Therefore, high professional standards and 
integrity in the agency's work are indispensable. The review and improvement of their activities are on-going so as to ensure that their services to institutions and society are optimal.

Agencies apply an internal quality assurance policy which is available on its website. This policy

- ensures that all persons involved in its activities are competent and act professionally and ethically;

- includes internal and external feedback mechanisms that lead to a continuous improvement within the agency;

- guards against intolerance of any kind or discrimination;

- outlines the appropriate communication with the relevant authorities of those jurisdictions where they operate;

- ensures that any activities carried out and material produced by subcontractors are in line with the ESG, if some or all of the elements in its quality assurance activities are subcontracted to other parties;

- allows the agency to establish the status and recognition of the institutions with which it conducts external quality assurance.

\subsection{Cyclical external Review of Agencies}

\section{STANDARD:}

Agencies should undergo an external review at least once every five years in order to demonstrate their compliance with the ESG.

\section{GUIDELINES:}

A periodic external review will help the agency to reflect on its policies and activities. It provides a means for assuring the agency and its stakeholders that it continues to adhere to the principles enshrined in the ESG. 


\section{Annex: SUmmary LiSt OF StANDARDS}

\section{Part 1: Standards for internal Quality assurance}

\subsection{Policy for Quality Assurance}

Institutions should have a policy for quality assurance that is made public and forms part of their strategic management. Internal stakeholders should develop and implement this policy through appropriate structures and processes, while involving external stakeholders.

\subsection{Design AND approval of programmes}

Institutions should have processes for the design and approval of their programmes. The programmes should be designed so that they meet the objectives set for them, including the intended learning outcomes. The qualification resulting from a programme should be clearly specified and communicated, and refer to the correct level of the national qualifications framework for higher education and, consequently, to the Framework for Qualifications of the European Higher Education Area.

\subsection{StUdent-CENTRED LEARNING, TEACHING AND ASSESSMENT}

Institutions should ensure that the programmes are delivered in a way that encourages students to take an active role in creating the learning process, and that the assessment of students reflects this approach.

\subsection{STUdENT ADMISSION, PROGRESSION, RECOGNITION AND CERTIFICATION}

Institutions should consistently apply pre-defined and published regulations covering all phases of the student "life cycle", e.g. student admission, progression, recognition and certification.

\subsection{Teaching StafF}

Institutions should assure themselves of the competence of their teachers. They should apply fair and transparent processes for the recruitment and development of the staff.

\subsection{LEARNING RESOURCES AND STUDENT SUPPORT}

Institutions should have appropriate funding for learning and teaching activities and ensure that adequate and readily accessible learning resources and student support are provided.

\subsection{INFORMATION MANAGEMENT}

Institutions should ensure that they collect, analyse and use relevant information for the effective management of their programmes and other activities.

\subsection{Public information}

Institutions should publish information about their activities, including programmes, which is clear, accurate, objective, up-to date and readily accessible.

\subsection{ON-GOING MONITORING AND PERIODIC REVIEW OF PROGRAMMES}

Institutions should monitor and periodically review their programmes to ensure that they achieve the objectives set for them and respond to the needs of students and society. These reviews should lead to continuous improvement of the programme. Any action planned or taken as a result should be communicated to all those concerned.

\subsection{CyCLical EXTERnAL QUALITY ASSURANCE}

Institutions should undergo external quality assurance in line with the ESG on a cyclical basis. 


\section{Part 2: Standards for external Quality assurance}

\subsection{Consideration OF INTERNAL Quality ASSURANCE}

External quality assurance should address the effectiveness of the internal quality assurance described in Part 1 of the ESG.

\subsection{Designing Methodologies Fit FOR PURPOSE}

External quality assurance should be defined and designed specifically to ensure its fitness to achieve the aims and objectives set for it, while taking into account relevant regulations. Stakeholders should be involved in its design and continuous improvement.

\subsection{ImPLEMENTING PROCESSES}

External quality assurance processes should be reliable, useful, pre-defined, implemented consistently and published. They include

- a self-assessment or equivalent;

- an external assessment normally including a site visit;

- a report resulting from the external assessment;

- a consistent follow-up.

\subsection{Peer-Review experts}

External quality assurance should be carried out by groups of external experts that include (a) student member(s).

\subsection{Criteria for outcomes}

Any outcomes or judgements made as the result of external quality assurance should be based on explicit and published criteria that are applied consistently, irrespective of whether the process leads to a formal decision.

\subsection{Reporting}

Full reports by the experts should be published, clear and accessible to the academic community, external partners and other interested individuals. If the agency takes any formal decision based on the reports, the decision should be published together with the report.

\subsection{Complaints ANd apPeals}

Complaints and appeals processes should be clearly defined as part of the design of external quality assurance processes and communicated to the institutions.

\section{Part 3: Standards for Quality assurance agencies}

\subsection{ACTIVITIES, POLICY AND PROCESSES FOR QUALITY ASSURANCE}

Agencies should undertake external quality assurance activities as defined in Part 2 of the ESG on a regular basis. They should have clear and explicit goals and objectives that are part of their publicly available mission statement. These should translate into the daily work of the agency. Agencies should ensure the involvement of stakeholders in their governance and work.

\subsection{Official status}

Agencies should have an established legal basis and should be formally recognised as quality assurance agencies by competent public authorities.

\subsection{INDEPENDENCE}

Agencies should be independent and act autonomously. They should have full responsibility for 
their operations and the outcomes of those operations without third party influence.

\subsection{Thematic analysis}

Agencies should regularly publish reports that describe and analyse the general findings of their external quality assurance activities.

\subsection{Resources}

Agencies should have adequate and appropriate resources, both human and financial, to carry out their work.

\subsection{INTERNAL QUALITY ASSURANCE AND PROFESSIONAL CONDUCT}

Agencies should have in place processes for internal quality assurance related to defining, assuring and enhancing the quality and integrity of their activities.

\subsection{Cyclical external review of agencies}

Agencies should undergo an external review at least once every five years in order to demonstrate their compliance with the ESG. 



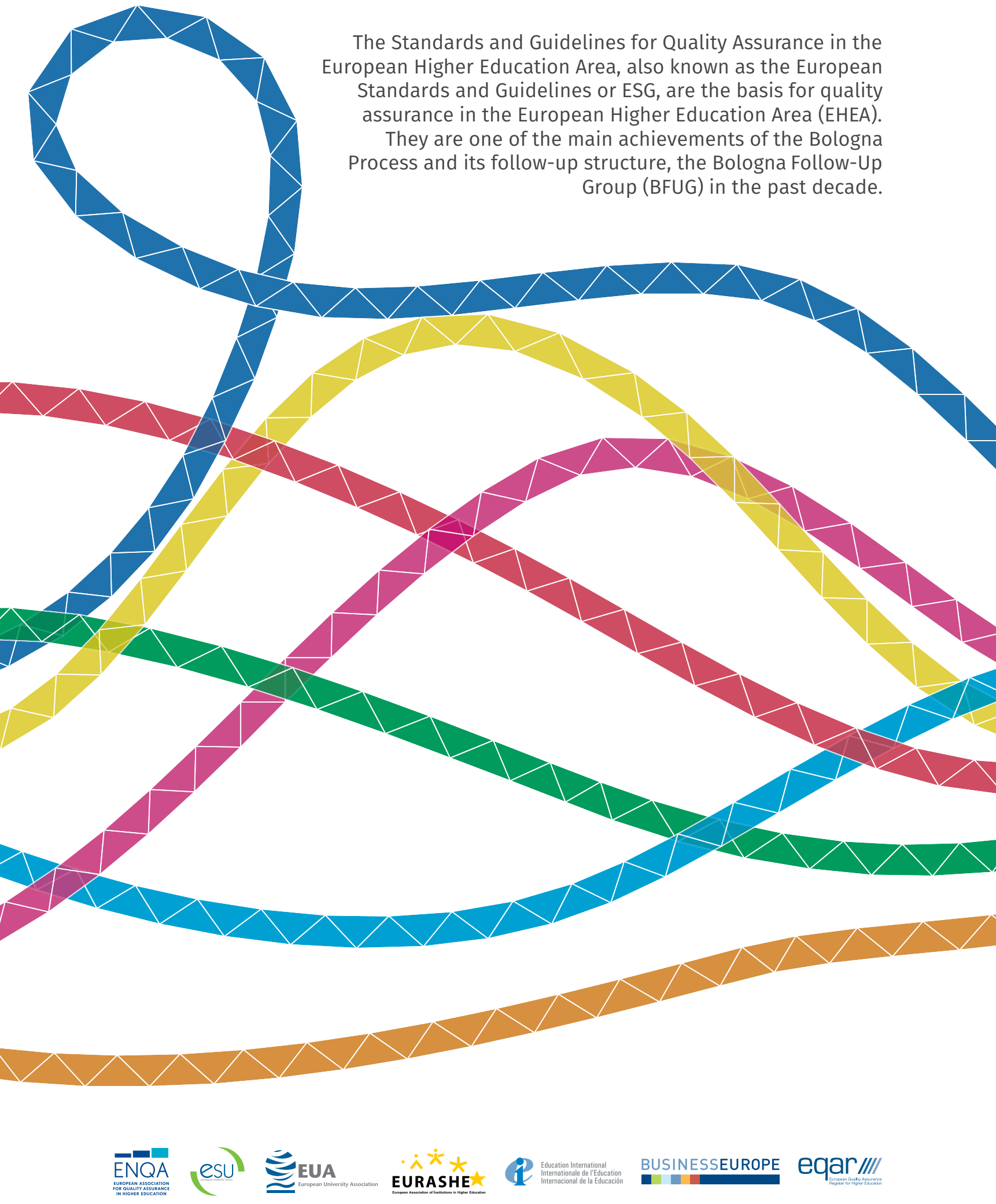